\title{
Frontotemporal dementia-amyotrophic lateral sclerosis syndrome locus on chromosome 16p12.1-q12.2: genetic, clinical and neuropathological analysis
}

\author{
Carol Dobson-Stone $\cdot$ Agnes A. Luty $\cdot$ Elizabeth M. Thompson - Peter Blumbergs $\cdot$ William S. Brooks • \\ Cathy L. Short • Colin D. Field · Peter K. Panegyres · Jane Hecker · Jennifer A. Solski - Ian P. Blair • \\ Janice M. Fullerton • Glenda M. Halliday $•$ Peter R. Schofield · John B. J. Kwok
}

Received: 31 July 2012/Revised: 7 January 2013/Accepted: 8 January 2013/Published online: 22 January 2013

(C) The Author(s) 2013. This article is published with open access at Springerlink.com

\begin{abstract}
Numerous families exhibiting both frontotemporal dementia (FTD) and amyotrophic lateral sclerosis (ALS) have been described, and although many of these have been shown to harbour a repeat expansion in C9ORF72, several C9ORF72-negative FTD-ALS families remain. We performed neuropathological and genetic analysis of a large European Australian kindred (Aus-12) with autosomal dominant inheritance of dementia and/or ALS. Affected Aus-12 members developed either ALS or dementia; some of those with dementia also had ALS and/ or extrapyramidal features. Neuropathology was most consistent with frontotemporal lobar degeneration with type B TDP pathology, but with additional phosphorylated tau pathology consistent with corticobasal degeneration. Aus-12 DNA samples were negative for mutations in all known dementia and ALS genes, including C9ORF72 and FUS. Genome-wide linkage analysis provided highly
\end{abstract}

C. Dobson-Stone and A. A. Luty are the equal first authors.

Electronic supplementary material The online version of this article (doi:10.1007/s00401-013-1078-9) contains supplementary material, which is available to authorized users.

C. Dobson-Stone - A. A. Luty - W. S. Brooks ·

J. M. Fullerton · G. M. Halliday · P. R. Schofield ·

J. B. J. Kwok $(\square)$

Neuroscience Research Australia, Barker St, Randwick,

Sydney, NSW 2031, Australia

e-mail: j.kwok@neura.edu.au

C. Dobson-Stone - A. A. Luty · W. S. Brooks ·

J. M. Fullerton - G. M. Halliday · P. R. Schofield · J. B. J. Kwok

University of New South Wales, Sydney, Australia

E. M. Thompson

SA Clinical Genetics Service, SA Pathology,

Women's and Children's Hospital, Adelaide, Australia suggestive evidence (maximum multipoint LOD score of 2.9) of a locus on chromosome 16p12.1-16q12.2. Affected individuals shared a chromosome 16 haplotype flanked by D16S3103 and D16S489, spanning $37.9 \mathrm{Mb}$, with a smaller suggestive disease haplotype spanning $24.4 \mathrm{Mb}$ defined by recombination in an elderly unaffected individual. Importantly, this smaller region does not overlap with FUS. Whole-exome sequencing identified four variants present in the maximal critical region that segregate with disease. Linkage analysis incorporating these variants generated a maximum multipoint LOD score of 3.0. These results support the identification of a locus on chromosome 16p12.1-16q12.2 responsible for an unusual cluster of neurodegenerative phenotypes. This region overlaps with a separate locus on 16q12.1-q12.2 reported in an independent ALS family, indicating that this region may harbour a second major locus for FTD-ALS.

Keywords Frontotemporal dementia .

Amyotrophic lateral sclerosis - Motor neuron disease .

Corticobasal degeneration $\cdot$ Tau $\cdot$ TDP-43

\author{
E. M. Thompson \\ Department of Paediatrics, University of Adelaide, \\ North Terrace, Adelaide, Australia \\ P. Blumbergs \\ Institute of Medical and Veterinary Science, \\ Adelaide, Australia \\ C. L. Short \\ Department of Neurology, The Queen Elizabeth Hospital, \\ Woodville, Adelaide, Australia
}




\section{Introduction}

Frontotemporal dementia (FTD) is a clinically and pathologically heterogeneous group of disorders that can present with personality and behavioural changes or language deficits [33]. The discovery of MAPT mutations in families with hereditary dementia with parkinsonism [16] allowed the unified classification of a group of families with a wide spectrum of clinical and pathological diagnoses. Dementia in these families was often atypical but most resembled FTD [27], with changes in personality, behaviour and insight, together with extrapyramidal motor features. Similarly, a group of MAPT-negative families with heterogeneous clinical features was later shown to have mutations in the granulin gene (GRN) [6]. Some families with GRN mutations have a diagnosis of corticobasal syndrome (CBS) [7, 30].

Amyotrophic lateral sclerosis (ALS) is characterised by degeneration of upper and lower motor neurons, leading to progressive muscle wasting, spasticity and ultimately paralysis and death. Families with hereditary dementia and ALS have been linked to a C9ORF72 hexanucleotide repeat expansion $[9,31]$. These families usually include some affected members with pure ALS, while the majority of affected members develop a dementia syndrome that is often atypical or difficult to diagnose, but in most cases eventually resembles FTD. Affected members with dementia may also develop ALS during the course of their disease. As well as MAPT, GRN and C9ORF72, other genes have been found to harbour mutations in families with FTD (e.g., $V C P, C H M P 2 B$ ) or ALS (e.g., SOD1, TARDBP, FUS) [3, 35].

Several types of neuropathology are found in patients with FTD, classified under the general rubric of frontotemporal lobar degeneration (FTLD). Most cases contain filamentous inclusions made of one of three constitutive

C. D. Field

Division of Rehabilitation and Aged Care, Memory Clinic,

Repatriation General Hospital, Daw Park, Adelaide, Australia

Present Address:

C. D. Field

Adelaide Dementia Driving Clinic, North Adelaide, Australia

P. K. Panegyres

Neurodegenerative Disorders Research Pty Ltd, Subiaco,

Perth, Australia

J. Hecker

Department of General Medicine, Royal Adelaide Hospital, Adelaide, Australia

J. A. Solski · I. P. Blair

Northcott Neuroscience Laboratory, ANZAC Research Institute,

Concord Hospital, Sydney, Australia neuronal proteins: tau (FTLD-tau), TAR DNA-binding protein (FTLD-TDP) or fused in sarcoma (FTLD-FUS) [22]. Cases with FTD-ALS most commonly have type B FTLD-TDP pathology characterised by motor neuron-like neuronal cytoplasmic inclusions (NCIs) [32]. In contrast, corticobasal degeneration (CBD) has a distinctive FTLDtau pathology with ballooned neurons and tau-immunoreactive astrocytic plaques and threads [10]. In this study, we describe a large multigenerational family (Aus-12) with a clinical spectrum of FTD and ALS, and neuropathology consistent with CBD FTLD-tau and type B FTLD-TDP. Combined genome-wide linkage and whole-exome sequencing analysis identified a disease locus on chromosome 16p12.1-16q12.2.

\section{Subjects and methods}

\section{Family recruitment}

The proband (IV:23) was referred to a memory clinic at age 56 with symptoms suggesting cognitive decline in the context of a family history of young-onset dementia. She subsequently visited a clinical genetics service, where a detailed family history was compiled including available medical records. Twelve individuals with dementia and two with ALS were identified over four generations in a pattern consistent with autosomal dominant inheritance. Approval to approach relatives for a family genetics study was granted by the Ethics Committee of the Women's and Children's Hospital, Adelaide, and genetic studies were approved by the Ethics Committee of Concord Hospital in Sydney. The next of kin of individuals IV:5 and IV:7 consented to an autopsy study for brain research at the time of death and tissue sections and neuropathological reports for this study were obtained from the South Australian Brain Bank. To determine final diagnoses for IV:5 and IV:7, a retrospective review of their neuropathology was performed using current diagnostic criteria for Alzheimer's disease, dementia with Lewy bodies, FTLD, ALS, and other neurodegenerative syndromes including $\mathrm{CBD}$, progressive supranuclear palsy, and vascular dementia $[8,10$, $15,17,22,24,26]$. Brain tissue from a previously published familial FTLD-TDP case with a R493X GRN mutation [29] and two neuropathologically confirmed CBD FTLD-tau cases, obtained from the Sydney Brain Bank, were examined for comparison.

Immunohistochemical analysis

Immunohistochemistry was performed on formalin-fixed paraffin-embedded 7-10- $\mu \mathrm{m}$ superior frontal cortex, hippocampus or spinal cord sections. We performed standard 
peroxidase immunohistochemistry with citrate buffer antigen retrieval and $0.5 \%$ cresyl violet counterstaining [19]. Antibodies used were for ubiquitin (Z0458, DAKO, Denmark, diluted 1:200), phosphorylated tau (MN1020, PIERCE, USA, diluted 1:10,000), phosphorylated TDP (BC001487, PTG, USA, diluted 1:500), FUS (HPA008784, Sigma, Australia, diluted 1:1,000), $\alpha$-internexin (32-3600, ZYMED Laboratories, USA, diluted 1:50) and phosphorylated $200 \mathrm{kD}$ neurofilament (MAS330, Seralab, UK, diluted 1:200). Reaction specificity was confirmed by omitting primary antibodies. Double immunofluorescent labelling was performed to detect phosphorylated tau and phosphorylated TDP. After antigen retrieval, sections were treated for autofluorescence by immersion in $0.25 \%$ potassium permanganate solution for $7 \mathrm{~min}$, rinsed with water and placed in $1 \%$ potassium metabisulphite, $1 \%$ oxalic acid until the sections returned to their original colour. Tau and TDP immunoreactivity was visualised with Alexa Fluor 568 goat anti-rabbit and Alexa Fluor 488 goat anti-mouse secondary antibodies (Invitrogen) on a confocal microscope (C190; Nikon Corporation, Tokyo, Japan). A section without primary antibodies was included for each staining procedure as a negative control. In addition, a mixture of the secondary antibodies was applied to sections with only one primary antibody incubated on each section.

FTLD-TDP was classified into one of four subtypes [21] based on the morphology and laminar distribution of TDPimmunopositive inclusions in the affected brain regions.

\section{Genetic evaluation of family}

Blood was collected from 13 family members and DNA extracted. DNA was screened for mutations in known dementia/ALS genes (Supplementary Table 1). A 10-cM genome-wide scan was performed on DNA from 12 individuals by the Australian Genome Research Facility (AGRF) with microsatellite markers from the ABI-400 set (ABI Prism Linkage Mapping Set, version 2.5, MD-10). Parametric pairwise and multipoint LOD scores were calculated and simulation analyses were performed using MERLIN v1.1.2 [2]. Autosomal dominant inheritance of a single genetic locus for all clinical variants was assumed with a phenocopy rate of 0.005 , a disease gene frequency of 0.001 and equal marker allele frequencies. Seven liability classes were established based on pedigree data with $1 \%$ penetrance-age $<25$ years, $8 \%$-between 26 and 34 years, $22 \%$-between 35 and 44 years, $46 \%$-between 45 and 54 years, $71 \%$ between 55 and 64 years, $91 \%$-between 65 and 74 years, and $95 \%$-age $>75$ years. Individuals were assigned a liability class based on age of onset for affected cases and age at last consultation for asymptomatic cases.

High-resolution fine mapping of chromosome 16 was performed at the AGRF using microsatellite markers selected from the UCSC Human Genome Browser Gateway (http://genome.ucsc.edu/cgi-bin/hgGateway). Primers were fluorescently labelled with 6-FAM and PCR was carried out according to standard protocols. For fine mapping, allele frequencies were derived from a cohort of European ancestry Australian normals [13], from CEPH family data (http://www.cephb.fr/en/cephdb/), or were assumed to be equal if information was unavailable. The novel markers $16 \mathrm{GT}$ and $21 \mathrm{AC}$ were amplified in-house and amplified products were run on the Applied Biosystems 3730 DNA Analyser at the Ramaciotti Centre, University of New South Wales. We generated allele frequencies for these markers from a panel of 24 unrelated European ancestry healthy controls.

Whole-exome sequencing was performed on one unaffected and four affected Aus-12 family members, using 100-bp paired-end sequencing on the Illumina HiSeq2000 with $40 \times$ coverage, by Macrogen (Seoul, Korea).

\section{Results}

\section{Clinical description of the Aus-12 family}

Family members of pedigree Aus-12 (Fig. 1) were the subjects of detailed clinical review (Table 1). The proband (IV:23) presented with memory impairments and was given a final clinical diagnosis of FTD. The proband's mother, III:17, died at 61 with dementia; four of her nine siblings were affected with dementia and died before age 65 . The proband's grandmother and great-grandmother were affected with dementia, dying at 64 and 40, respectively. Four first cousins of the proband had presenile dementia; two died with ALS aged 45 and 49 years, respectively; and one was diagnosed with FTD-ALS. Detailed clinical notes for pedigree members IV:23, IV:5, IV:7 and IV:12 are available in Supplementary Material.

Neuropathological analysis of Aus-12

Case IV:5 The brain weighed 1,003 g. Microscopy confirmed severe fronto-temporal atrophy with diffuse neuronal loss and reactive gliosis maximal in the temporal poles where status spongiosis was present (Supplementary Table 2). The main immunocytochemical pathology was that of a tauopathy with the phospho-tau (AT8) immunostains showing prominent cytoplasmic neuronal reactivity ("pre-tangles") and occasional neurofibrillary tangles involving subsets of hippocampal CA1 pyramidal neurons, temporal neocortex, frontal and parietal cortex in association with numerous AT8 immunoreactive neuronal threads (Fig. 2a-c). There was limited overall loss of hippocampal CA1 neurons (Fig. 2e). Many of the dentate granule cells showed phospho-tau 


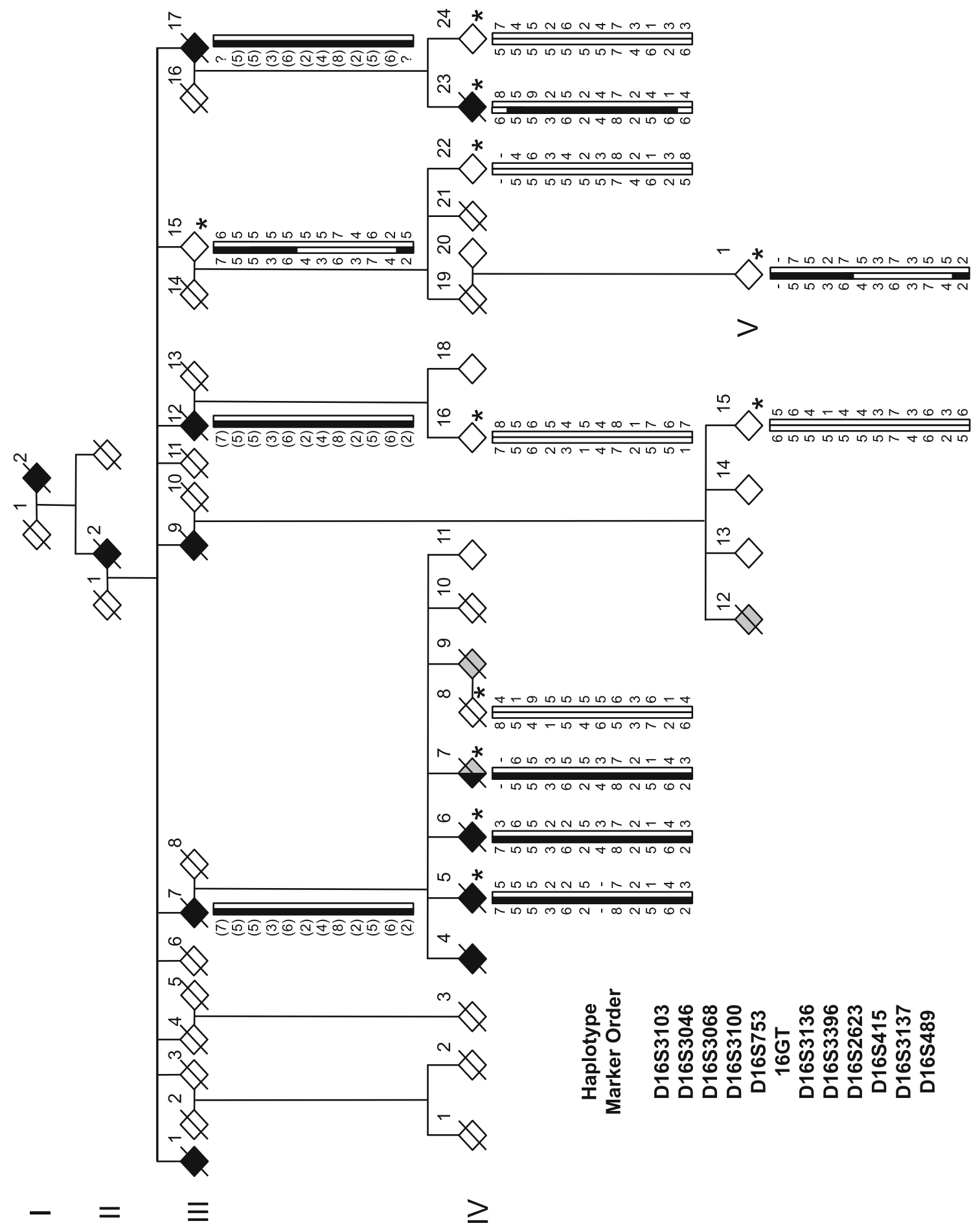

Fig. 1 Haplotype analysis of the chromosome 16p12.3-16q12.2 region in family Aus-12. Black symbols show individuals with dementia, either AD or FTD; grey symbols individuals with ALS. A diagonal line marks deceased subjects. Individuals with DNA

cytoplasmic immunoreactivity (Fig. 2c). Occasional phosphorylated neurofilament and tau immunopositive 'ballooned neurons' were noted in the frontal and hippocampal sections but this was a rare finding. Phospho-tau immunoreactive available are asterisked. Inferred haplotypes are in parentheses. Allele data for 12 markers in this region are shown. Some haplotypes were presented for review but have been omitted from publication, to protect confidentiality of at-risk individuals

astrocytic plaques (Fig. 2d) and coiled fibres were also present. A prominent subset of neurons in the nucleus basalis of Meynert showed AT8 immunoreactive cytoplasmic staining in association with numerous positive neuronal threads. 
Table 1 Clinical summary of family Aus-12

\begin{tabular}{llll}
\hline Subject & Age at onset (years) & Age at death (years) & Diagnosis/clinical features \\
\hline I:2 & 30 & 40 & Died after 10 years in psychiatric hospital \\
II:2 & 56 & 64 & 'Presenile Alzheimer's disease' \\
III: 1 & 53 & 59 & 'Inherited dementia' \\
III:7 & 49 & 56 & Unspecified presenile dementia \\
III:9 & $?$ & 64 & Unspecified presenile dementia \\
III:12 & $?$ & 62 & Memory loss, apathy, lacked insight \\
III:17 & 51 & 61 & Memory loss, wandering, behavioural problems \\
IV:4 & 56 & 68 & Memory loss, behavioural problems \\
IV:5 & 54 & 64 & 'FTD with aphasia' \\
IV:6 & 58 & 67 & Unspecified presenile dementia \\
IV:7 & 62 & 69 & FTD-ALS, Paget's disease, parkinsonism \\
IV:9 & $?$ & 45 & Probable ALS \\
IV:12 & $?$ & 49 & ALS \\
IV:23 & 56 & 68 & FTD \\
\hline
\end{tabular}

Subsets of neurons and astrocytes in the caudate nucleus showed positive AT8 cytoplasmic immunostaining, whereas in the putamen and globus pallidus astrocyte immunoreactivity was more prominent than neuronal staining. PhosphoTDP-43 immunoreactive NCIs were found in both superficial and deep cortical laminae of the frontal (Fig. 2f, inset) and temporal cortex. A subset of the dentate granule cells showed phospho-TDP-43 immunopositive NCIs (Fig. 2f). Double labelling immunofluorescence revealed that cytoplasmic phospho-tau immunoreactivity and phospho-TDP-43 immunopositive NCIs were found together in approximately $20 \%$ of hippocampal dentate granule cells and $5 \%$ of cortical neurons (Supplementary Fig. 1c, f, j, k). While many neurons and glia contained AT8 immunoreactivity (Supplementary Fig. 1a, d, g), a minority of phospho-TDP-43 immunopositive NCIs were found in neurons that were not immunoreactive for phospho-tau (Supplementary Fig. 1c, k). No FUS or $\alpha$-internexin immunoreactive inclusion pathology was observed. In the midbrain there was neuronal loss, depigmentation and gliosis of the substantia nigra. A subset of surviving substantia nigra neurons showed cytoplasmic AT8 immunoreactivity, as did scattered periaqueductal neurons in association with immunoreactive neurites. The AT8 immunostains also showed intracytoplasmic staining in neurons of the locus coeruleus, scattered neurons of midline raphe nuclei, dorsal motor vagal nuclei, nuclei ambiguii and reticular formation in association with immunoreactive neurites. The findings are those of CBD FTLD-tau associated with type B FTLD-TDP without significant bulbar motor neuron involvement.

Case IV:7 The brain weighed 1,160 g. There was more severe frontotemporal atrophy in this case, and the substantia nigra was severely depigmented. Microscopy showed a similar pattern and type of neuropathological features to those described above but with greater neuronal loss
(Supplementary Table 2), consistent with more advanced CBD FTLD-tau and type B FTLD-TDP. Western blot analysis of the sarkosyl-insoluble fraction of frontal pole tissue revealed that the insoluble tau species present in this case was consistent with a 4-repeat tauopathy, as seen with other CBD cases [5, 34] (Supplementary Fig. 2). The spinal cord was also available in this case and segmental sections showed preservation of the corticospinal tracts (myelin stain). There was patchy loss of anterior horn cells in the cervical and thoracic spinal cord segments and ubiquitinated, neurofilament-immunoreactive motor neurons, neurites (Fig. $2 \mathrm{~g}, \mathrm{~h}$ ) and NCI (Fig. 2g, inset) were observed in these sections, along with rare phospho-tau immunoreactivity (Fig. 2i). Phospho-TDP immunoreactivity was restricted to neurites and granular staining in small neurons (Fig. 2j) and absent in anterior horn cells. No FUS or $\alpha$-internexin immunoreactivity was observed in these spinal cord sections.

The phospho-tau neuropathology of Aus-12 cases closely resembled that in the CBD FTLD-tau cases examined. The TDP-43 neuropathology was similar in amount and distribution but not structural type to that observed in the $G R N$ mutation-positive FTLD-TDP case. Greater deposition in the dentate gyrus and fewer phospho-TDP-positive neurites was observed in the Aus-12 cases (Supplementary Material). The motor neuron involvement was mild compared with classic end-stage ALS cases and was without TDP or FUS deposition, although ubiquitinated inclusions were present (as has been observed in other familial ALS cases negative for known mutations) [23].

Genetic analysis of Aus-12

DNA from IV:5, IV:6 and IV:24 was subjected to DNA sequence analysis of the coding regions and flanking 


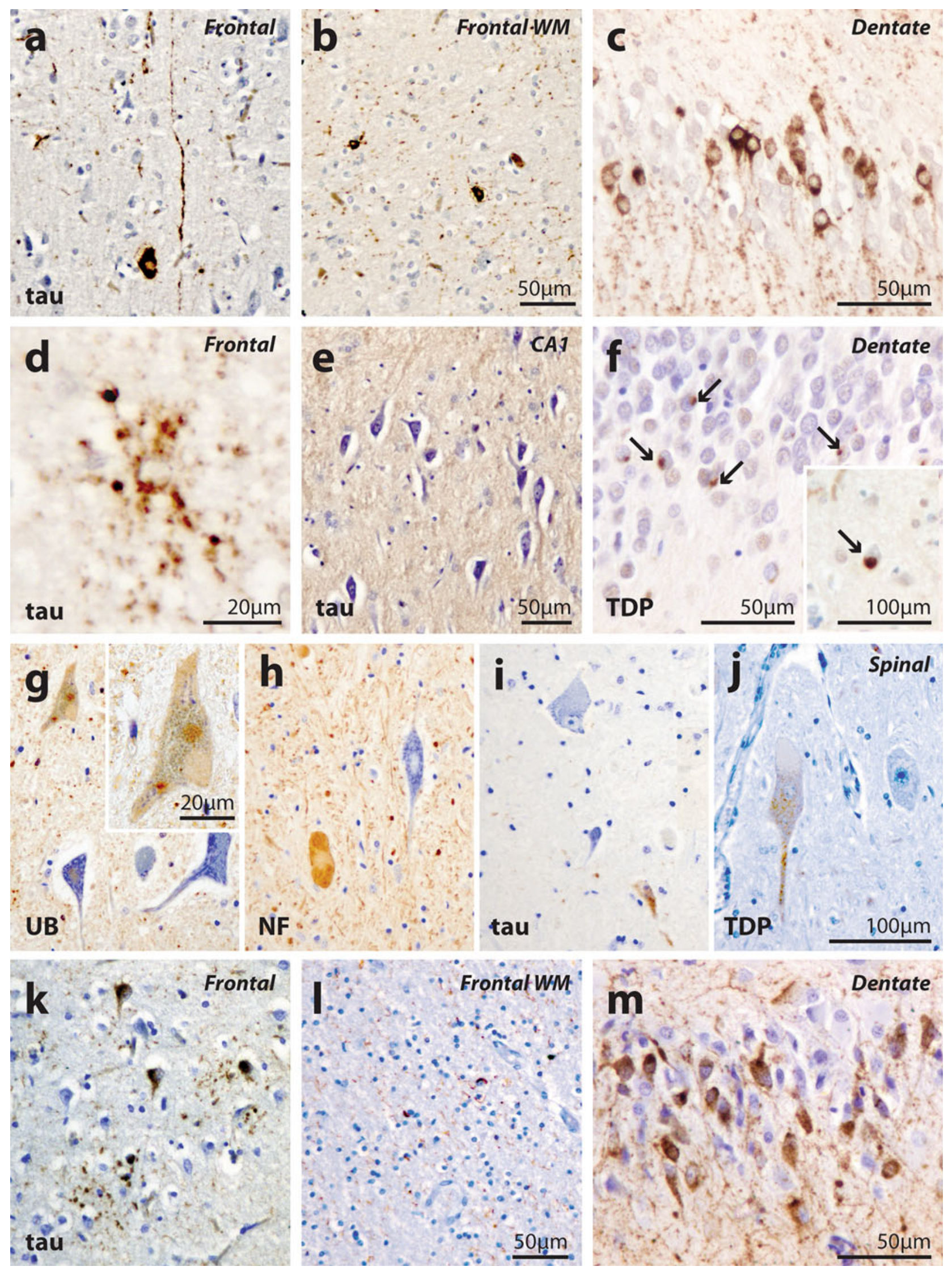


4Fig. 2 Phospho-tau and phospho-TDP neuropathology in case IV:5 (a-f), case IV:7 (g-j) and an independent CBD FTLD-tau case $(\mathbf{k}-\mathbf{m})$. Numerous phospho-tau-immunopositive threads in the frontal cortex (a) and white matter (b). c Dentate granule cells showing extensive phospho-tau immunoreactivity. d Phospho-tau-immunoreactive astrocytic plaque in frontal cortex. e Nissl staining showing limited loss of CA1 hippocampal pyramidal neurons. Phospho-TDP-immunopositive NCIs (arrows) in the dentate gyrus (f) and frontal cortex (f, inset). Ubiquitin- (g) and phosphorylated $200 \mathrm{kD}$ neurofilament- (h) immunopositive motor neurons, NCI and neurites in the cervical spinal cord. Rare phospho-tau immunoreactivity was observed in neurites, glia and small spinal cord neurons (i) and some phospho-TDPimmunopositive granules were observed in spinal motor neurons in the absence of TDP-positive inclusions (j). In the case of sporadic CBD ( $\mathbf{k}-\mathbf{m})$, phospho-tau-immunoreactive astrocytic plaques, neurons and threads were seen in the frontal cortex (k), phospho-tauimmunoreactive glia and threads in the white matter (l), and diffuse cytoplasmic phospho-tau immunoreactivity was observed in the dentate granule cells $(\mathbf{m})$

intronic sequences for known dementia and ALS genes (Supplementary Table 1). No mutations were detected.

We undertook a genome-wide linkage analysis on 12 pedigree members, five of whom were classed as affected. Six regions generated two-point LOD scores $\geq 1$, on chromosomes 3 (D3S1285, LOD = 1.3), 12 (D12S352, 1.0), 15 (D15S117, 1.5; D15S127, 1.1), 16 (D16S415, 1.2) and 20 (D20S107, 1.4); however, with multipoint analysis the only regions with a LOD score $\geq 1$ were on chromosome 16 (D16S415, LOD = 2.7; D16S516, 1.1). Examination of haplotypes revealed that affected individual IV-23 was identical by state rather than by descent at D16S516: this individual harboured the same haplotype as unaffected sibling IV-24 at D16S516 and flanking markers D16S515 and D16S3091 (data not shown). In contrast, alleles at D16S415 and upstream markers D16S3046, D16S3068 and D16S3136 were shared by all affected individuals. This region on chromosome 16 was therefore fine mapped with 21 additional markers. Supplementary Table 3 details two-point LOD scores, showing a maximum of $2.4(\theta=0)$ at D16S3396. Gene-dropping simulation analyses indicated that two chromosome 16 microsatellite markers exceeded the genome-wide $1 \%$ significance threshold for 100 simulations. Multipoint analysis with MERLIN yielded a maximum LOD score of 2.9 for all markers from D16S753 to D16S2623 inclusive and excluded linkage (LOD $<-2)$ at other FTD loci (CHMP2B, C9ORF72, VCP, GRN/MAPT) (Supplementary Fig. 3).

Haplotypes were constructed for the 16p12.1-q12.2 region in Aus-12 (Fig. 1). Recombinations in this family defined a $37.9-\mathrm{Mb}$ region flanked by the markers D16S3103 and D16S489, in which a common haplotype was shared by all affected individuals (Fig. 3b). A smaller suggestive disease haplotype spanning $24.4 \mathrm{Mb}$ was defined by recombination at D16S753 in elderly unaffected individual III:15. This region overlaps with a separate locus on 16q12.1-q12.2 reported in an ALS family by Abalkhail et al. [1] (Fig. 3b).

We performed whole-exome sequencing of affected individuals IV:5, IV:6, IV:17, IV:23 and elderly unaffected individual III:15. No pathogenic variants were identified in known dementia or ALS genes, including FUS on chromosome 16 (Supplementary Table 1). We identified seven variants from the exome sequencing data within the Aus-12 maximal critical region that were absent from dbSNP131, and were detected in at least 2 affected individuals and resequenced them in all 13 Aus-12 DNA samples. Four variants were present in all affected individuals and absent in the elderly unaffected individual, two of which were also absent from public databases of normal human variation (Table 2). One of these variants, g.48576222C $>$ A, was detected in 2/934 healthy Australian individuals of European ancestry by examination of exome sequencing data (Dr Paul Leo and Prof Matthew Brown, personal communication). The second variant, g.50825515A $>$ G, leads to the substitution of methionine to valine at amino acid position 719 of the cylindromatosis protein, CYLD. This variant is present within the region of overlap with the chromosome 16q12.1-linked ALS pedigree [1] (Table 2).

We used nine rare variants detected by whole-exome sequencing and confirmed by Sanger sequencing to repeat the linkage analysis. This generated a maximum two-point LOD score of 2.7 for markers g.31484758G $>$ A, g. $48576222 \mathrm{C}>\mathrm{A}$, g. $50825515 \mathrm{~A}>\mathrm{G}$ and g.53721944A $>\mathrm{G}$ (Supplementary Table 3) and a maximum multipoint LOD score of 3.0 for markers $16 \mathrm{GT}$ through to g.53721944A $>\mathrm{G}$ inclusive (Fig. 3a).

\section{Discussion}

In this study, we describe a complex FTD-ALS family with co-existing CBD and TDP neuropathology. The clinical presentations in this family are heterogeneous. The majority of the affected individuals presented initially with AD-like symptoms and/or motor disorders, rather than the typical presentation of FTD. For example, the proband (IV:23) presented with AD-like symptoms, but soon after developed significant personality and behavioural change, with disinhibition, socially inappropriate and obsessional behaviour, and a lack of insight and was diagnosed with FTD. Early memory impairment suggestive of $\mathrm{AD}$ is also observed amongst GRN mutation carriers [18, 30], sometimes in association with motor disorders. Patient IV:7, who was initially diagnosed with Paget's disease, later developed clinical symptoms consistent with parkinsonism and ALS. ALS was also present as a pure syndrome in two other family members. In MAPT mutation carriers, ALS tends to be a late manifestation in patients already afflicted 

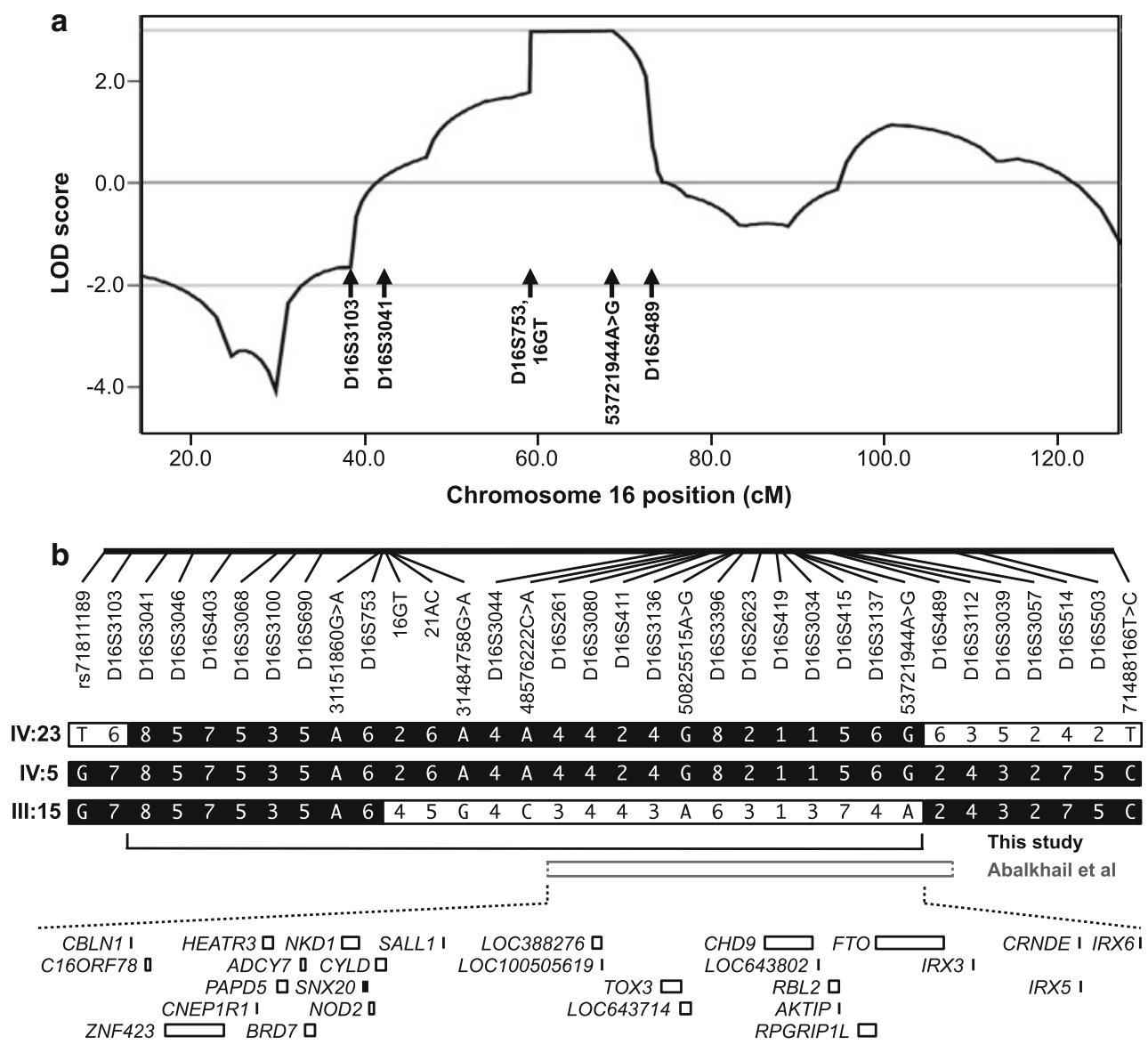

Fig. 3 Linkage analysis of Aus-12. a Multipoint linkage analysis of chromosome 16, generated using MERLIN program. Positions of markers flanking critical recombinations in Aus-12 family members are indicated. b Haplotype analysis of chromosome 16p13.11-16q22.2. Top Physical positions of microsatellite markers and single-nucleotide variants used for haplotype analysis. Middle Haplotypes of affected

with parkinsonism, rather than a separate entity [20, 37]. Thus, clinical heterogeneity is not uncommon and has been described in other families with GRN and MAPT mutations.

The Aus-12 pedigree represents the first to our knowledge in which affected individuals have neuropathologically confirmed CBD FTLD-tau as well as type B FTLD-TDP. Concomitant phospho-tau and phospho-TDP neuropathology is not rare and has now been reported in many different sporadic neurodegenerative disorders, but particularly in $\mathrm{AD}$ and $\mathrm{CBD}$ [36]. Interestingly, although ALS is usually characterised by TDP-43 pathology [4, 28], studies have demonstrated significant deposition of phospho-tau in brains of ALS patients with cognitive impairment [14, 38]. Our western blot analyses (Supplementary Fig. 2) clearly show that the insoluble tau species comprise solely four repeat isoforms. This finding corresponds to a pathological diagnosis of CBD or PSP, rather than Pick's disease [11]. To further differentiate between these two individuals IV:23 and IV:5 and elderly unaffected individual III:15. The disease haplotype is indicated in black. The maximal critical region defined in this study and the critical region detected in the ALS family reported in Abalkhail et al. [1] are depicted below. Bottom RefSeq genes present in the minimal critical region, defined by overlap of Aus-12 and Abalkhail et al. critical regions

highly related disorders would require the presence of balloon neurons (Fig. 2) and astrocytic plaques for CBD, or globose tangles and tufted astrocytes for PSP, or perhaps the identification of a low molecular weight tau species that co-migrates with CBD and not PSP protein species [11]. The underlying phospho-TDP neuropathology of IV:5 and IV:7 was consistent with type B TDP-43 neuropathology, a pathology described in most familial FTD-ALS cases arising from C9ORF72 mutation [12, 25]. However, the spinal cord TDP pathology was more limited, characterised by the occasional staining of neurites, with the ubiquitinated motor neuron inclusions not immunoreactive for TDP or tau. Co-immunofluorescence analysis revealed considerable overlap between the brain regions affected by the phospho-tau and phospho-TDP pathology, although both pathologies occurred independently, and more phospho-tau was observed in these cases. While the neuropathological depositions appear 
Table 2 Variants detected by whole-exome sequencing

\begin{tabular}{|c|c|c|c|c|c|c|}
\hline gDNA change ${ }^{a}$ & Gene & Variant type & Segregates with disease? ${ }^{\mathrm{b}}$ & MAF $1000 G^{c}$ & MA count EVS ${ }^{\mathrm{d}}$ & $\begin{array}{l}\text { MAF used for } \\
\text { linkage analysis }\end{array}$ \\
\hline g. $31151860 \mathrm{G}>\mathrm{A}$ & PRSS36 & Missense (p.P707L) & No & $(\mathrm{RNC})$ & $18 / 8,548$ & 0.002 \\
\hline g. $31447539 \mathrm{G}>\mathrm{A}$ & ZNF843 & Missense (p.P211L) & No & 0 & $0 / 3,182$ & 0.001 \\
\hline g. $31484758 \mathrm{G}>\mathrm{A}$ & TGFB1I1 & Intronic (c.IVS1-4G >A) & Yes & 0.0118 & $109 / 8600$ & 0.012 \\
\hline g. $48576222 \mathrm{C}>\mathrm{A}$ & $N 4 B P 1$ & $3^{\prime} \mathrm{UTR}(\mathrm{c} .2691 * 593 \mathrm{C}>\mathrm{A})$ & Yes & 0 & $(\mathrm{RNC})$ & 0.001 \\
\hline g.50825515A>G & $C Y L D$ & Missense (p.M719V) & Yes & $\mathbf{0}$ & $\mathbf{0} / \mathbf{8 , 1 3 8}$ & 0.001 \\
\hline g.53653005G $>C$ & RPGRIPIL & Missense (p.A1183G) & No & 0.0176 & 132/8,600 & 0.016 \\
\hline g.53721944A>G & RPGRIPIL & Intronic (c.IVS4-67A>G) & Yes & 0.0059 & (RNC) & 0.0059 \\
\hline g.71488166T $>C^{\mathrm{e}}$ & ZNF23 & Intronic (c.IVS3-45T>C) & No & 0.0059 & $(\mathrm{RNC})$ & 0.0059 \\
\hline
\end{tabular}

$M A$ minor allele, $M A F$ minor allele frequency, $R N C$ region not covered

${ }^{a}$ Variants present in region of overlap with a chromosome 16q12.1-linked ALS pedigree [1] are in bold. Variant nomenclature is according to the recommendations of the Human Genome Variation Society (http://www.hgvs.org/mutnomen/). Genomic co-ordinates on chromosome 16 refer to the human reference sequence GRCh37/hg19

${ }^{\mathrm{b}}$ Presence in all affected individuals and absence in elderly unaffected individuals

${ }^{c}$ Frequency in CEU population of the 1,000 Genomes dataset (http://www.ncbi.nlm.nih.gov/variation/tools/1000genomes/)

${ }^{\mathrm{d}}$ Count in European American population of the Exome Variant Server (http://evs.gs.washington.edu/EVS/)

e Variant lies outside Aus-12 maximal critical region

unique in family Aus-12, the relationship between the pathologies observed remains unclear.

Genome-wide linkage analysis resulted in the identification of a disease locus on chromosome 16p12.1-q12.2. The region overlaps with a known ALS/FTD gene, FUS (OMIM *137070). However, we did not detect any FUS mutations in Aus-12, using both Sanger sequencing and whole-exome sequencing. Individuals IV:17 and IV:23 are heterozygous for SNP rs741810 in FUS exon 3 and IV:5 and IV:6 are heterozygous for rs1052352 in exon 4, indicating that both alleles are present at this locus. In addition, the smaller suggestive region defined by recombination in individual III:15 does not include the FUS locus. Intriguingly, the Aus-12 disease region overlaps with that identified in an independent ALS family (Fig. 3b), with maximal multipoint LOD scores of 2.06 at D16S3080 and D16S411 [1]. This ALS family is negative for FUS mutations and the hexanucleotide repeat expansion in $C 9 O R F 72$ (Prof Jacqueline de Belleroche, personal communication). Assuming that the disease in this family is due to the same genetic cause, the recombination breakpoint observed in this study at D16S489 slightly narrows the telomeric boundary of the combined published minimal disease region by $26 \mathrm{~kb}$. This combined critical region contains 27 RefSeq genes (Fig. 3b). We detected one nonsynonymous variant within these genes by whole-exome sequencing: Met719Val in CYLD. CYLD was previously sequenced in affected individuals from the Abalkhail et al. [1] ALS pedigree but no mutations were identified (Prof Jacqueline de Belleroche, personal communication). CYLD Met-719 is invariant in mammals, chicken, frog and zebrafish, but is valine in Drosophila CYLD homologues (data not shown).
In silico analysis using programs Align GVGD (http:// agvgd.iarc.fr/agvgd_input.php/), PolyPhen-2 (http://gene tics.bwh.harvard.edu/pph2/) and SIFT (http://sift.jcvi. org/) predicted that this substitution was not likely to be pathogenic. This implies that the disease variant is either located in non-exonic sequence or is of a type that cannot be detected by direct sequencing, such as a genomic rearrangement, copy-number variant, or a repeat expansion.

The identification of two independent families with linkage to the same locus indicates that this region may harbour a second major FTD-ALS gene. The positional cloning of the major FTD causative loci have been instrumental in the elucidation of pathogenic mechanisms underlying the various neuropathological variants, including MAPT and GRN [6, 16]. Genetic evaluation of family Aus-12 will further aid our understanding of disease pathogenesis in FTD-ALS cases with both phospho-tau and phospho-TDP deposition.

Acknowledgments We thank all patients and family members who participated in this study. We would like to thank Jacqueline de Belleroche for discussion of her work, Paul Leo and Matthew Brown for access to control exome data, Marianne Hallupp, Amanda Gysbers, Karen E. Murphy and Heather McCann for laboratory assistance, and Heidi Cartwright for figurework. Tissues were received from the South Australian Brain Bank and the Sydney Brain Bank, which are supported by the Australian Brain Bank Network, with funding from the National Health and Medical Research Council of Australia (NHMRC) and the FMC Foundation. The Sydney Brain Bank is also supported by Neuroscience Research Australia and the University of New South Wales. This study was funded by an Australian Postgraduate Award (A.A.L.), NHMRC Research Fellowships 157209 (P.R.S.) and 630434 (G.M.H.), and Project Grants 276401 (P.R.S., J.B.J.K. and W.S.B.), 510217 (J.B.J.K. and P.R.S.) and 630428 (C.D.-S.). 
Conflict of interest The authors declare that they have no conflict of interest.

Open Access This article is distributed under the terms of the Creative Commons Attribution License which permits any use, distribution, and reproduction in any medium, provided the original author(s) and the source are credited.

\section{References}

1. Abalkhail H, Mitchell J, Habgood J, Orrell R, de Belleroche J (2003) A new familial amyotrophic lateral sclerosis locus on chromosome 16q12.1-16q12.2. Am J Hum Genet 73:383-389

2. Abecasis GR, Cherny SS, Cookson WO, Cardon LR (2002) Merlin-rapid analysis of dense genetic maps using sparse gene flow trees. Nat Genet 30:97-101

3. Al-Chalabi A, Jones A, Troakes C, King A, Al-Sarraj S, van den Berg LH (2012) The genetics and neuropathology of amyotrophic lateral sclerosis. Acta Neuropathol 124:339-352

4. Arai T, Hasegawa M, Akiyama H, Ikeda K, Nonaka T, Mori H, Mann D, Tsuchiya K, Yoshida M, Hashizume Y, Oda T (2006) TDP-43 is a component of ubiquitin-positive tau-negative inclusions in frontotemporal lobar degeneration and amyotrophic lateral sclerosis. Biochem Biophys Res Commun 351:602-611

5. Arai T, Ikeda K, Akiyama H, Shikamoto Y, Tsuchiya K, Yagishita S, Beach T, Rogers J, Schwab C, McGeer PL (2001) Distinct isoforms of tau aggregated in neurons and glial cells in brains of patients with Pick's disease, corticobasal degeneration and progressive supranuclear palsy. Acta Neuropathol 101:167-173

6. Baker M, Mackenzie IR, Pickering-Brown SM, Gass J, Rademakers R, Lindholm C, Snowden J, Adamson J, Sadovnick AD, Rollinson S, Cannon A, Dwosh E, Neary D, Melquist S, Richardson A, Dickson D, Berger Z, Eriksen J, Robinson T, Zehr C, Dickey CA, Crook R, McGowan E, Mann D, Boeve B, Feldman H, Hutton M (2006) Mutations in progranulin cause tau-negative frontotemporal dementia linked to chromosome 17. Nature 442:916-919

7. Boeve BF, Lang AE, Litvan I (2003) Corticobasal degeneration and its relationship to progressive supranuclear palsy and frontotemporal dementia. Ann Neurol 54(Suppl 5):S15-S19

8. Brooks BR (1994) El Escorial World Federation of Neurology criteria for the diagnosis of amyotrophic lateral sclerosis. Subcommittee on Motor Neuron Diseases/Amyotrophic Lateral Sclerosis of the World Federation of Neurology Research Group on Neuromuscular Diseases and the El Escorial "Clinical limits of amyotrophic lateral sclerosis" workshop contributors. J Neurol Sci 124(Suppl):96-107

9. DeJesus-Hernandez M, Mackenzie IR, Boeve BF, Boxer AL, Baker M, Rutherford NJ, Nicholson AM, Finch NA, Flynn H, Adamson J, Kouri N, Wojtas A, Sengdy P, Hsiung GY, Karydas A, Seeley WW, Josephs KA, Coppola G, Geschwind DH, Wszolek ZK, Feldman H, Knopman DS, Petersen RC, Miller BL, Dickson DW, Boylan KB, Graff-Radford NR, Rademakers R (2011) Expanded GGGGCC hexanucleotide repeat in noncoding region of C9ORF72 causes chromosome 9p-linked FTD and ALS. Neuron 72:245-256

10. Dickson DW, Bergeron C, Chin SS, Duyckaerts C, Horoupian D, Ikeda K, Jellinger K, Lantos PL, Lippa CF, Mirra SS, Tabaton M, Vonsattel JP, Wakabayashi K, Litvan I (2002) Office of rare diseases neuropathologic criteria for corticobasal degeneration. J Neuropathol Exp Neurol 61:935-946

11. Dickson DW, Kouri N, Murray ME, Josephs KA (2011) Neuropathology of frontotemporal lobar degeneration-tau (FTLD-tau). J Mol Neurosci 45:384-389
12. Dobson-Stone C, Hallupp M, Bartley L, Shepherd CE, Halliday GM, Schofield PR, Hodges JR, Kwok JBJ (2012) C9ORF72 repeat expansion in clinical and neuropathological frontotemporal dementia cohorts. Neurology 79:995-1001

13. Fullerton JM, Donald JA, Mitchell PB, Schofield PR (2010) Twodimensional genome scan identifies multiple genetic interactions in bipolar affective disorder. Biol Psychiatry 67:478-486

14. Gohar M, Yang W, Strong W, Volkening K, Leystra-Lantz C, Strong MJ (2009) Tau phosphorylation at threonine-175 leads to fibril formation and enhanced cell death: implications for amyotrophic lateral sclerosis with cognitive impairment. J Neurochem 108:634-643

15. Hauw JJ, Daniel SE, Dickson D, Horoupian DS, Jellinger K, Lantos PL, McKee A, Tabaton M, Litvan I (1994) Preliminary NINDS neuropathologic criteria for Steele-Richardson-Olszewski syndrome (progressive supranuclear palsy). Neurology 44:20152019

16. Hutton M, Lendon CL, Rizzu P, Baker M, Froelich S, Houlden H, Pickering-Brown S, Chakraverty S, Isaacs A, Grover A, Hackett J, Adamson J, Lincoln S, Dickson D, Davies P, Petersen RC, Stevens M, de Graaff E, Wauters E, van Baren J, Hillebrand M, Joosse M, Kwon JM, Nowotny P, Che LK, Norton J, Morris JC, Reed LA, Trojanowski J, Basun H, Lannfelt L, Neystat M, Fahn S, Dark F, Tannenberg T, Dodd PR, Hayward N, Kwok JB, Schofield PR, Andreadis A, Snowden J, Craufurd D, Neary D, Owen F, Oostra BA, Hardy J, Goate A, van Swieten J, Mann D, Lynch T, Heutink P (1998) Association of missense and 5'-splicesite mutations in tau with the inherited dementia FTDP-17. Nature 393:702-705

17. Hyman BT, Trojanowski JQ (1997) Consensus recommendations for the postmortem diagnosis of Alzheimer disease from the National Institute on Aging and the Reagan Institute Working Group on diagnostic criteria for the neuropathological assessment of Alzheimer disease. J Neuropathol Exp Neurol 56:1095-1097

18. Kelley BJ, Haidar W, Boeve BF, Baker M, Graff-Radford NR, Krefft T, Frank AR, Jack CR Jr, Shiung M, Knopman DS, Josephs KA, Parashos SA, Rademakers R, Hutton M, PickeringBrown S, Adamson J, Kuntz KM, Dickson DW, Parisi JE, Smith GE, Ivnik RJ, Petersen RC (2009) Prominent phenotypic variability associated with mutations in Progranulin. Neurobiol Aging 30:739-751

19. Luty AA, Kwok JB, Thompson EM, Blumbergs P, Brooks WS, Loy CT, Dobson-Stone C, Panegyres PK, Hecker J, Nicholson GA, Halliday GM, Schofield PR (2008) Pedigree with frontotemporal lobar degeneration-motor neuron disease and Tar DNA binding protein-43 positive neuropathology: genetic linkage to chromosome 9. BMC Neurol 8:32

20. Lynch T, Sano M, Marder KS, Bell KL, Foster NL, Defendini RF, Sima AA, Keohane C, Nygaard TG, Fahn S et al (1994) Clinical characteristics of a family with chromosome 17-linked disinhibition-dementia-parkinsonism-amyotrophy complex. Neurology 44:1878-1884

21. Mackenzie IR, Neumann M, Baborie A, Sampathu DM, Du Plessis D, Jaros E, Perry RH, Trojanowski JQ, Mann DM, Lee VM (2011) A harmonized classification system for FTLD-TDP pathology. Acta Neuropathol 122:111-113

22. Mackenzie IR, Neumann M, Bigio EH, Cairns NJ, Alafuzoff I, Kril J, Kovacs GG, Ghetti B, Halliday G, Holm IE, Ince PG, Kamphorst W, Revesz T, Rozemuller AJ, Kumar-Singh S, Akiyama H, Baborie A, Spina S, Dickson DW, Trojanowski JQ, Mann DM (2010) Nomenclature and nosology for neuropathologic subtypes of frontotemporal lobar degeneration: an update. Acta Neuropathol 119:1-4

23. Maekawa S, Leigh PN, King A, Jones E, Steele JC, Bodi I, Shaw CE, Hortobagyi T, Al-Sarraj S (2009) TDP-43 is consistently colocalized with ubiquitinated inclusions in sporadic and Guam 
amyotrophic lateral sclerosis but not in familial amyotrophic lateral sclerosis with and without SOD1 mutations. Neuropathology 29:672-683

24. McKeith IG, Dickson DW, Lowe J, Emre M, O'Brien JT, Feldman H, Cummings J, Duda JE, Lippa C, Perry EK, Aarsland D, Arai H, Ballard CG, Boeve B, Burn DJ, Costa D, Del Ser T, Dubois B, Galasko D, Gauthier S, Goetz CG, Gomez-Tortosa E, Halliday G, Hansen LA, Hardy J, Iwatsubo T, Kalaria RN, Kaufer D, Kenny RA, Korczyn A, Kosaka K, Lee VM, Lees A, Litvan I, Londos E, Lopez OL, Minoshima S, Mizuno Y, Molina JA, Mukaetova-Ladinska EB, Pasquier F, Perry RH, Schulz JB, Trojanowski JQ, Yamada M (2005) Diagnosis and management of dementia with Lewy bodies: third report of the DLB consortium. Neurology 65:1863-1872

25. Murray ME, DeJesus-Hernandez M, Rutherford NJ, Baker M, Duara R, Graff-Radford NR, Wszolek ZK, Ferman TJ, Josephs KA, Boylan KB, Rademakers R, Dickson DW (2011) Clinical and neuropathologic heterogeneity of c9FTD/ALS associated with hexanucleotide repeat expansion in C9ORF72. Acta Neuropathol 122:673-690

26. Nagata K, Saito H, Ueno T, Sato M, Nakase T, Maeda T, Satoh Y, Komatsu H, Suzuki M, Kondoh Y (2007) Clinical diagnosis of vascular dementia. J Neurol Sci 257:44-48

27. Neary D, Snowden JS, Gustafson L, Passant U, Stuss D, Black S, Freedman M, Kertesz A, Robert PH, Albert M, Boone K, Miller BL, Cummings J, Benson DF (1998) Frontotemporal lobar degeneration: a consensus on clinical diagnostic criteria. Neurology 51:1546-1554

28. Neumann M, Sampathu DM, Kwong LK, Truax AC, Micsenyi MC, Chou TT, Bruce J, Schuck T, Grossman M, Clark CM, McCluskey LF, Miller BL, Masliah E, Mackenzie IR, Feldman H, Feiden W, Kretzschmar HA, Trojanowski JQ, Lee VM (2006) Ubiquitinated TDP-43 in frontotemporal lobar degeneration and amyotrophic lateral sclerosis. Science 314:130-133

29. Pickering-Brown SM, Baker M, Gass J, Boeve BF, Loy CT, Brooks WS, Mackenzie IR, Martins RN, Kwok JB, Halliday GM, Kril J, Schofield PR, Mann DM, Hutton M (2006) Mutations in progranulin explain atypical phenotypes with variants in MAPT. Brain 129:3124-3126

30. Rademakers R, Baker M, Gass J, Adamson J, Huey ED, Momeni P, Spina S, Coppola G, Karydas AM, Stewart H, Johnson N, Hsiung GY, Kelley B, Kuntz K, Steinbart E, Wood EM, Yu CE, Josephs K, Sorenson E, Womack KB, Weintraub S, PickeringBrown SM, Schofield PR, Brooks WS, Van Deerlin VM, Snowden J, Clark CM, Kertesz A, Boylan K, Ghetti B, Neary D, Schellenberg GD, Beach TG, Mesulam M, Mann D, Grafman J, Mackenzie IR, Feldman H, Bird T, Petersen R, Knopman D, Boeve B, Geschwind DH, Miller B, Wszolek Z, Lippa C, Bigio EH, Dickson D, Graff-Radford N, Hutton M (2007) Phenotypic variability associated with progranulin haploinsufficiency in patients with the common $1477 \mathrm{C} \rightarrow \mathrm{T}(\mathrm{Arg} 493 \mathrm{X})$ mutation: an international initiative. Lancet Neurol 6:857-868

31. Renton AE, Majounie E, Waite A, Simon-Sanchez J, Rollinson S, Gibbs JR, Schymick JC, Laaksovirta H, van Swieten JC, Myllykangas L, Kalimo H, Paetau A, Abramzon Y, Remes AM, Kaganovich A, Scholz SW, Duckworth J, Ding J, Harmer DW, Hernandez DG, Johnson JO, Mok K, Ryten M, Trabzuni D, Guerreiro RJ, Orrell RW, Neal J, Murray A, Pearson J, Jansen IE, Sondervan D, Seelaar H, Blake D, Young K, Halliwell N, Callister JB, Toulson G, Richardson A, Gerhard A, Snowden J, Mann D, Neary D, Nalls MA, Peuralinna T, Jansson L, Isoviita VM, Kaivorinne AL, Holtta-Vuori M, Ikonen E, Sulkava R, Benatar M, Wuu J, Chio A, Restagno G, Borghero G, Sabatelli M, Heckerman D, Rogaeva E, Zinman L, Rothstein JD, Sendtner M, Drepper C, Eichler EE, Alkan C, Abdullaev Z, Pack SD, Dutra A, Pak E, Hardy J, Singleton A, Williams NM, Heutink P, Pickering-Brown S, Morris HR, Tienari PJ, Traynor BJ (2011) A hexanucleotide repeat expansion in C9ORF72 is the cause of chromosome 9p21-linked ALS-FTD. Neuron 72:257-268

32. Sampathu DM, Neumann M, Kwong LK, Chou TT, Micsenyi M, Truax A, Bruce J, Grossman M, Trojanowski JQ, Lee VM (2006) Pathological heterogeneity of frontotemporal lobar degeneration with ubiquitin-positive inclusions delineated by ubiquitin immunohistochemistry and novel monoclonal antibodies. Am J Pathol 169:1343-1352

33. Sieben A, Van Langenhove T, Engelborghs S, Martin JJ, Boon P, Cras P, De Deyn PP, Santens P, Van Broeckhoven C, Cruts M (2012) The genetics and neuropathology of frontotemporal lobar degeneration. Acta Neuropathol 124:353-372

34. Sergeant N, Wattez A, Delacourte A (1999) Neurofibrillary degeneration in progressive supranuclear palsy and corticobasal degeneration: tau pathologies with exclusively "exon 10" isoforms. J Neurochem 72:1243-1249

35. Sleegers K, Cruts M, Van Broeckhoven C (2010) Molecular pathways of frontotemporal lobar degeneration. Annu Rev Neurosci 33:71-88

36. Uryu K, Nakashima-Yasuda H, Forman MS, Kwong LK, Clark CM, Grossman M, Miller BL, Kretzschmar HA, Lee VM, Trojanowski JQ, Neumann M (2008) Concomitant TAR-DNAbinding protein 43 pathology is present in Alzheimer disease and corticobasal degeneration but not in other tauopathies. J Neuropathol Exp Neurol 67:555-564

37. Wszolek ZK, Vieregge $P$, Uitti RJ, Gasser T, Yasuhara $\mathrm{O}$, McGeer P, Berry K, Calne DB, Vingerhoets FJ, Klein C, Pfeiffer RF (1997) German-Canadian family (family A) with parkinsonism, amyotrophy, and dementia-longitudinal observations. Parkinsonism Relat Disord 3:125-139

38. Yang W, Strong MJ (2012) Widespread neuronal and glial hyperphosphorylated tau deposition in ALS with cognitive impairment. Amyotroph Lateral Scler 13:178-193 